\title{
Loss of imagery phenomenology with intact visuo-spatial task performance: A case of 'blind imagination'
}

\author{
Adam Z.J. Zeman ${ }^{\mathrm{a}}$, Sergio Della Sala ${ }^{\mathrm{b}, *}$, Lorna A. Torrens ${ }^{\mathrm{c}}$, Viktoria-Eleni Gountouna ${ }^{\mathrm{b}}$, \\ David J. McGonigle ${ }^{\mathrm{d}, 1}$, Robert H. Logie ${ }^{\mathrm{b}}$ \\ a Department of Neurology, Peninsula Medical School, Exeter, UK \\ ${ }^{\mathrm{b}}$ Human Cognitive Neuroscience and Centre for Cognitive Ageing and Cognitive Epidemiology, Psychology, University of Edinburgh, Edinburgh, UK \\ ${ }^{\mathrm{c}}$ Robert Fergusson Unit, Royal Edinburgh Hospital, Edinburgh, UK \\ d Centre for Functional Imaging Studies, Western General Hospital, Edinburgh, UK
}

\section{A R T I C L E I N F O}

\section{Article history:}

Received 19 October 2008

Received in revised form 25 August 2009

Accepted 27 August 2009

Available online 3 September 2009

\section{Keywords:}

Visual imagery

Phenomenology

Face perception

\begin{abstract}
A B S T R A C T
The capacity for imagery, enabling us to visualise absent items and events, is a ubiquitous feature of our experience. This paper describes the case of a patient, MX, who abruptly lost the ability to generate visual images. He rated himself as experiencing almost no imagery on standard questionnaires, yet performed normally on standard tests of perception, visual imagery and visual memory. These unexpected findings were explored using functional MRI scanning (fMRI). Activation patterns while viewing famous faces were not significantly different between MX and controls, including expected activity in the fusiform gyrus. However, during attempted imagery, activation in MX's brain was significantly reduced in a network of posterior regions while activity in frontal regions was increased compared to controls. These findings are interpreted as suggesting that MX adopted a different cognitive strategy from controls when performing the imagery task. Evidence from experimental tasks thought to rely on mental imagery, such as the Brooks' matrices and mental rotation, support this interpretation. Taken together, these results indicate that successful performance in visual imagery and visual memory tasks can be dissociated from the phenomenal experience of visual imagery.
\end{abstract}

(c) 2009 Elsevier Ltd. All rights reserved.

\section{Introduction}

Asked to imagine a familiar item or recall a recent event, most people can call to mind an image that is less vivid than the original but has a visual 'feel'. This expresses our capacity to experience visual mental imagery. There is a long-standing debate (see review in Bartolomeo, 2008) as to whether this mental experience plays a functional role in cognition: one view suggests that propositional knowledge is sufficient for supporting performance in imagery tasks (e.g. Pylyshyn, 2002), the other that imagery plays a key functional role (Kosslyn, Thomson \& Ganis, 2006; Paivio, 1971). It could be that a range of cognitive strategies might be available to participants in these tasks. For example, imagery tasks might be performed using imagery or by using a propositional strategy. Both strategies might be available to healthy adults, although there is

\footnotetext{
* Corresponding author at: Human Cognitive Neuroscience, Psychology, Edinburgh University, 7 George Square, Edinburgh EH8 9JZ, UK.

E-mail address: sergio@ed.ac.uk (S. Della Sala).

${ }^{1}$ Current address: Schools of Psychology and Biosciences, Cardiff University, Cardiff, Wales, UK.
}

a wide variation in the extent to which people report the experience of visual imagery (e.g. Marks, 1973; McKelvie, 1995; Reisberg, Kosslyn \& Pearson, 2003). Some subjects may, in other words, have a capacity for 'blind imagination', successful use of an alternative strategy to perform imagery tasks in the absence of the experience of imagery. This can be thought as analogous to the phenomenon of 'blindsight', characterized by successful performance in visuomotor tasks in the absence of visual perceptual experience.

We describe the case of an individual (MX) who reported the sudden loss of the experience of visual imagery in the absence of any other cognitive deficits. In previous published studies, the loss of visual imagery has been accompanied by impairments in performance on imagery tasks, for example in patients who show severe impairments on imagery tests but have intact perception (e.g. Farah, 1984; Bartolomeo, 2002; Kaski, 2002; Moro, Berlucchi, Lerch, Tomaiuolo \& Aglioti, 2008) and in patients who show pure representational neglect but no perceptual neglect (Guariglia, Padovani, Pantano \& Pizzamiglio, 1993; Beschin, Cocchini, Della Sala \& Logie, 1997). In striking contrast, despite giving a persuasive description of his mental imagery deficit, MX was unimpaired on a range of standard tests of visual imagery. The main aim of this paper is to investigate the basis for the apparent dissociation between the 
Table 1

Neuropsychological test results for MX and matched controls.

\begin{tabular}{|c|c|c|c|c|c|}
\hline & MX & Control behaviour mean $N=3$ & Control behaviour SD & Control fMRI mean $N=10$ & Control fMRI SD \\
\hline \multicolumn{6}{|l|}{ WAIS-III } \\
\hline VIQ & 134 & 132 & 1.7 & 136.9 & 8.5 \\
\hline PIQ & 130 & 139 & 14.1 & 136.8 & 13.6 \\
\hline FSIQ & 136 & 139 & 6.5 & 140.5 & 9.8 \\
\hline $\mathrm{VCI}$ & 126 & 132 & 1.7 & 135.3 & 4.6 \\
\hline POI & 128 & 140 & 15.0 & 135.9 & 14.4 \\
\hline WMI & 128 & 122 & 3.6 & 124.1 & 11.7 \\
\hline PSI & 120 & 117 & 12.5 & 117.8 & 8.7 \\
\hline \multicolumn{6}{|l|}{ WMS-III } \\
\hline $\mathrm{AI}$ & 127 & 119 & 13.6 & 119 & 13.7 \\
\hline VI & 106 & 105 & 15.1 & 104.5 & 12.8 \\
\hline IM & 120 & 114 & 17.1 & 114.3 & 14.5 \\
\hline $\mathrm{AD}$ & 128 & 119 & 8.1 & 117.5 & 12.9 \\
\hline VD & 112 & 117 & 13.7 & 110.5 & 15.3 \\
\hline GM & 128 & 121 & 15.3. & 115.8 & 10.0 \\
\hline WM & 124 & 128 & 2.3 & 115.9 & 18.9 \\
\hline \multicolumn{6}{|l|}{ Imagery questionnaires } \\
\hline VVIQ $(/ 80)$ & $16^{* *}$ & 59 & 9.5 & 66 & 8.7 \\
\hline SUIS (/60) & $21^{*}$ & 37 & 3.8 & 42.3 & 7.3 \\
\hline \multicolumn{6}{|l|}{ Imagery tests } \\
\hline Animal tails $(/ 40)$ & $36^{\mathrm{a}}$ & & & & \\
\hline Letter forms i $(/ 26)$ & $26^{a}$ & & & & \\
\hline Letter forms ii (/26) & $25^{a}$ & & & & \\
\hline High imagery questions (/17) & $17^{\mathrm{a}}$ & & & & \\
\hline Mannekins (/32) & $32^{\mathrm{a}}$ & & & & \\
\hline Famous Face Feature (/66) & 46 & 46.6 & 1.5 & & \\
\hline Facial expression feature $(/ 36)$ & 24 & 28 & 3.6 & & \\
\hline
\end{tabular}

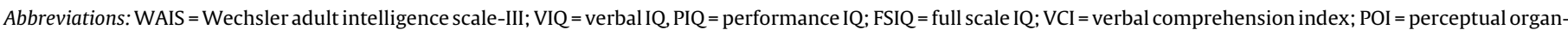

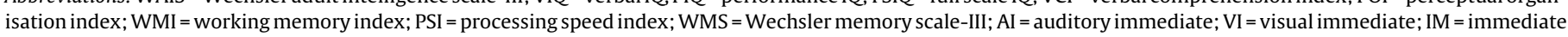

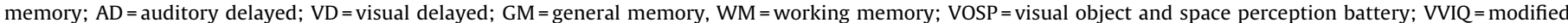
vividness of visual imagery questionnaire; SUIS = spontaneous use of imagery scale.

${ }^{*} p<0.02$ (comparison for MX vs. fMRI control group).

** $p<0.001$ (comparison for MX vs. fMRI control group).

a MX was at or close to ceiling and therefore no control data were collected.

lack of phenomenological experience in MX and his good performance.

Charcot and Bernard (1883, cited in Young \& van de Wal, 1996) anecdotally described the case of an individual 'Monsieur $\mathrm{X}$ ' who reported sudden onset of an inability to experience visual images of objects, such as monuments and buildings, and of familiar people such as close relatives. In this early case the visual imagery deficit was accompanied by some degree of prosopagnosia and clear visual memory impairments. Botez, Olivier, Vézina, Botez and Kaufman (1985) described the single case of a 38-year-old teacher presenting with an inability to experience visual images from birth in the absence of any overt deficits in perception, immediate or delayed visual memory. This example of a more selective deficit suggests that performance on visual imagery tasks might be normal in the absence of a phenomenal experience of visual imagery.

More comparable to MX are the two cases reported by Brain (1954) of sudden onset loss of visualisation, following head injury. One of these worked as a builder who, following a car accident, reported that he could no longer mentally visualise plans for new buildings, or even familiar routes, in stark contrast to his previous experience. Nevertheless he had no difficulty in drawing building plans. The second case sustained a head injury when tripping at work, and subsequently was unable to visualise recently viewed scenes or pages recently read from a book, although his reading and writing remained unimpaired. He also reported being unable to "see anything" when he closed his eyes. However, he could draw a plan of his house or a route from the station. These cases were not tested systematically on the imagery tasks developed from the 1970s onwards, nor, of course, was there any opportunity for detailed structural or functional neuroimaging. Nevertheless, as Brain himself recognised, his cases suggest the existence of dissoci- ation between the (lost) phenomenological experience associated with visual imagery and performance on visual imagery tasks, which was largely intact.

Standard assessment of visual imagery abilities requires subjects to recall visual details, such as the relative length of animals' tails, or to manipulate shapes 'in the mind's eye', for example to decide whether two shapes are in fact two views of a single object. Success in such tasks clearly requires access to a mental representation of the relevant material; it is not clear, however, that it always requires visualisation, the phenomenal experience of a visual image. There may be multiple routes to success in such tasks. For example, if asked about the colour of your mother's eyes you might answer by visualising her face and reading the answer off the resulting mental image, but it is possible to perform the same task by 'just knowing' the answer. These alternative strategies have been the focus of the polarised debate (Kosslyn et al., 2006; Pylyshyn, 2002) about whether mental imagery always serves a genuine cognitive function. We will return to the interpretation of our findings, and the imagery debate, in the discussion.

\section{Case report}

MX (not actual initials), a 65-year-old recently retired surveyor, accustomed to visualising buildings in his profession, and the faces of friends and family and recent events as he dropped off to sleep, abruptly lost the ability to visualise. His dreams lost their visual content. About 4 days before, he had undergone coronary angioplasty (remodelling of coronary arteries performed from within the arteries), experiencing brief 'reverberation in my head and tingling in my left arm'. These symptoms, experienced during the 
procedure, were not prominent and were not considered significant at the time. Neurological and ophthalmological assessments were normal. Psychiatric assessment was also normal, with no evidence of any psychiatric cause for his reported loss of imagery. Psychometric results are described below. Structural MRI showed minor white matter high intensities and borderline fronto-temporal atrophy, neither clearly falling outside the normal limits for his age. He had no difficulty recognising familiar faces from his circle of relatives and friends or when asked to identify famous faces (film stars, pop stars and British royalty) from photographs. When formally tested with the Graded Naming, Faces and Buildings tests (Ahmed, Arnold, Thomson, Graham \& Hodges, 2008) he performed well within the normal range. He also had no difficulty navigating around familiar environments, describing familiar routes or drawing pictures from memory. For example, he easily found the laboratory within the hospital without assistance. He could give detailed descriptions of scenes and landmarks around Edinburgh, including visual details: when asked how he could do this he commented: 'I can remember visual details, but I can't see them . . .. I can't explain that .... From time to time I do miss being able to see' (MX, in conversation with the authors). One year later he remained unable to summon visual imagery at will, or to imagine faces of close relatives or friends. He would occasionally experience a fleeting visual image if a familiar place was named during conversation, but he was unable to sustain such images, or to induce them voluntarily. He did not experience such fleeting imagery for other types of visual item, such as faces. He reported, however, that his dreams had regained their visual qualities.

\section{Psychometric testing}

\subsection{Methods}

We performed a wide-ranging neuropsychological assessment, comparing the performance of MX on relevant measures with performance of 10 control participants (or in some cases a subgroup of three control participants). The control participants were matched for age (mean 63.4 years, range 55-76), sex (male), IQ and professional background with MX (all were architects). We administered the following standard and bespoke tests: (i) IQ: Wechsler adult intelligence scale-III; (ii) memory: (a) Wechsler memory scale-III; (b) autobiographical memory interview (AMI-Kopelman, Wilson \& Baddeley, 1990); (iii) executive functions: (a) behavioural assessment of dysexecutive syndrome (Wilson, Alderman, Burgess, Emslie \& Evans, 1996); (b) Stroop test (Stroop, 1935), (c) modified Wisconsin card sorting test (Nelson, 1976); (iv) perception: visual object and space perception battery (Warrington \& James, 1991); (v) subjective vividness of visual imagery: (a) a modified version of the vividness of visual imagery questionnaire (Marks, 1973); (b) spontaneous use of imagery scale (Reisberg et al., 2003); (vi) 'imagery abilities': (a) animals' tails test (Behrmann, Moscovitch \& Winocur, 1994); (b) letter form tests (requiring judgements about whether letters extend 'below the line' or have curved parts-Weber \& Castleman, 1970; van der Meulen, Logie \& Della Sala, 2008); (c) high imagery questions (for example: 'Is the green of grass darker than the green of a pine tree?') (Eddy \& Glass, 1981); (d) Mannikin test (requiring mental rotation in space-Ratcliff, 1979); (e) famous face feature test (a demanding tailor-made test requiring judgements about visual details of familiar faces); (f) facial expression feature test (a demanding tailor-made test requiring judgements about visual features associated with facial expressions of basic emotions). Example questions for these two tailor made tests are given in Appendix A. The hospital anxiety and depression scale (HADS-Zigmond \& Snaith, 1983) was administered and a psychiatric interview was performed.

\subsection{Results}

Psychometric results are summarised in Table 1. MX was well matched with control participants on all measures of general intelligence and memory (full scale IQ 136 in MX, vs. 141 in control participants; general memory quotient 128 in MX vs. 116 in control participants). Immediate and delayed visual memory scores $(106,112)$ were lower than auditory memory scores $(127,128)$, but unimpaired by comparison with control participants. The WAIS-III and WMS-III were repeated after an interval of 1 year when the results were unchanged. His scores on the autobiographical memory interview (AMI-Kopelman et al., 1990) were at or close to ceiling for both semantic and personal memories from childhood, early adulthood and recent life. He was in the normal range on all subtests of the visual object and space perception battery. He was unimpaired on several measures of visual imagery. He performed at or close to ceiling on the animals' tails, letter forms and manikin tests and high imagery questions. He was unimpaired on two demanding tailor-made tests of visual memory, requiring judgements about the features of famous faces and emotional expressions. He also performed normally on measures of executive function: specifically he was classed as 'good' on the six element test from the BADS (Wilson et al., 1996). His performance was at the 100th centile on the Stroop test (Stroop, 1935), and he made no errors in swapping categories on the modified Wisconsin card sorting test (Nelson, 1976). There was no evidence of psychiatric disorder from the HADS or from psychiatric interview. However, his scores on self-report measures of visual imagery remained substantially lower than all of the control participants.

\section{Neuroimaging}

Given the apparent inconsistency between MX's insistence that he was unable to experience visual imagery and his normal performance on visual imagery tasks, we used fMRI to investigate JC's brain activation directly during attempted visual imagery.

A set of tasks was adapted from those used by Ishai, Haxby and Ungerleider (2002) in which healthy young adult participants were asked to view pictures of famous faces (perception condition) or to generate mental images (imagery condition) of famous faces in response to their visually presented names. Control stimuli were visually scrambled pictures of faces, ${ }^{2}$ for the perception condition, and strings of random letters, for the imagery condition. In the face perception condition, Ishai et al. (2002) reported increased activation (relative to the scrambled faces control) in the inferior occipital gyri, lateral fusiform gyri, superior temporal sulcus and the amygdala. Subsets of these same areas were activated relative to the random letter strings control during the imagery condition, with additional activation in the bilateral calcarine, hippocampus, precuneus, intraparietal sulcus and inferior frontal gyrus. On the basis of the evidence we have reported thus far, we predicted that MX would show a similar pattern to that of control participants for the perception condition, but an abnormal pattern of brain activation for the imagery condition.

\subsection{Participants and psychometric testing}

MX was assessed along with 10 right-handed healthy participants matched with MX on age, sex, and occupation (all were surveyors or architects). The age range for the controls was 55-76

\footnotetext{
2 These appear as abstract patterns in different shades of gray, and were not possible to identify as a recognisable object or face. We are grateful to Dr Ishai for providing these stimuli, using the same algorithms as in Ishai et al. (2002).
} 
years, mean 63.4, and none had any past history of neurological or psychiatric disorder or obvious current cognitive symptoms. All reported that they experienced mental imagery and none had noticed any recent change in the quality of that experience. All had normal structural MRI scans for their age. Psychometric test results for the controls are shown in Table 1.

\subsection{Experimental protocol}

First, all participants completed a shortened version of the experimental protocol within a full scale fMRI simulator to familiarize themselves with the scanning environment, and to avoid an effect of the scanning environment on performance or on the strategies that participants adopted on the tasks (e.g. Mazard et al., 2002). This session also served as practice on the task using a different set of stimuli from those used in the main experimental scanning. The period between the session in the simulator and the session in the real scanner varied from a few hours to 2 days, depending on the availability of each participant.

The simulator was built to match the physical characteristics of the GE scanner (described below). Participants lay supine in the bore of the simulator and a recording of echo-planar noise from the GE scanner was played at $85 \mathrm{db}$ as ambient noise. Experimental stimuli were presented using E-Prime software (1.1 SP3; Psychology Software Tools Inc.) on an LCD screen $(640 \times 480$ pixels) positioned in a simulator head coil. Within the GE scanner, the E-Prime software was running on the IFIS-SA fMRI system (Invivo Corp., Gainesville, FL).

Participants viewed stimuli in blocks belonging to four different classes-'perception': black and white images of famous faces; 'perception control': scrambled face stimuli; 'imagery': names of famous faces; 'imagery control': nonsense letter strings. Each block began with a presentation of the block's identity (e.g. 'imagery' $-1 \mathrm{~s}$ duration). In the perception conditions 5 different image stimuli were presented in one block, lasting for $5.8 \mathrm{~s}$ each. In the imagery conditions 5 different text stimuli were presented, each lasting for $800 \mathrm{~ms}$ with a $5 \mathrm{~s}$ inter-stimulus interval. In the perception blocks, participants were required to attempt to recognise the faces shown. In the imagery blocks, they had to imagine the face of the individual whose name was shown. In both control conditions, they merely had to attend to the stimuli and try to avoid using any kind of mental imagery. During each block, participants were required to press a button when each stimulus was presented, and participants fixated on a fixation cross when no stimuli or block instructions were present.

In the simulator each condition was presented twice. In the real scanner the procedure was identical, except that each condition was presented 7 times in total. No stimulus was repeated in the experiment (a total of 35 in each condition, all different from those used in the simulator).

\subsection{Data acquisition}

Data were acquired at the SFC Brain Imaging Centre (Edinburgh, UK) on a $1.5 \mathrm{~T}$ scanner (Signa LX, GE Medical, USA) equipped with echospeed gradients using a standard quadrature head coil. Functional MRI was performed with a blood oxygenation level-dependent (BOLD) sensitive $\mathrm{T} 2{ }^{*}$-weighted gradient echo EPI sequence (field of view [FOV]: $22 \mathrm{~cm}$; time to echo [TE]: $40 \mathrm{~ms}$; volume acquisition time [TR]: $2.5 \mathrm{~s}$; matrix size: $64 \times 64$; orientation: axial; slice thickness: $5 \mathrm{~mm}$ ). Three hundred and forty whole brain volumes were collected within a single EPI run. Anatomical $\mathrm{T} 1$ images were also acquired to facilitate anatomical localization of activations ( $1 \mathrm{~mm}$ pixel size; 3D inversion recovery-prepared T1-weighted sequence; inversion time $[\mathrm{TI}]=600 \mathrm{~ms}$; orientation: coronal; slice thickness: $1.7 \mathrm{~mm}$ ).
Table 2

Cluster sizes and significant $t$ values for contrasts between perception and perception control conditions for control participants.

\begin{tabular}{lcrrrr}
\hline Anatomical area & Cluster size $k$ & Voxel $t$ & $X$ & $Y$ & $Z$ \\
\hline Frontal lobes: & & & & & \\
L inferior frontal gyrus & 172 & 7.29 & -52 & 20 & 14 \\
L inferior frontal gyrus & & 5.13 & -48 & 18 & 30 \\
L inferior frontal gyrus & 71 & 5.77 & -38 & 26 & 0 \\
L inferior frontal gyrus & & 5.24 & -50 & 18 & -2 \\
Parietal lobes: & & & & & \\
L precuneus & 20 & 5.80 & 2 & -72 & 18 \\
Temporal lobes: & & & & & \\
L middle temporal gyrus & 72 & 11.34 & -64 & -30 & -4 \\
L fusiform gyrus & 137 & 8.11 & -42 & -50 & -20 \\
R fusiform gyrus & 36 & 6.44 & 42 & -46 & -26 \\
Occipital lobes: & & & & & \\
R inferior occipital gyrus & 177 & 6.73 & 48 & -84 & -10 \\
R inferior occipital gyrus & & 5.64 & 46 & -78 & -16 \\
R inferior occipital gyrus & & 5.13 & 40 & -78 & -4 \\
\hline
\end{tabular}

Results of group-level analysis, 1 -sample $t, \mathrm{df}=9$. All reported clusters contained at least 20 voxels and had peaks significant at $p<0.05$ corrected using FDR. Coordinates are in MNI space as reported by SPM2.

\section{4. fMRI data analysis}

Subject-specific data were processed with statistical parametric mapping (SPM) software SPM2 (Wellcome Department of Cognitive Neurology; www.fil.ion.ucl.ac.uk/spm) running on Matlab 6.5.1 (Mathworks). After removal of the first four volumes to account for T1 saturation effects, cerebral volumes were realigned

Table 3

Cluster sizes and significant $t$ values for contrasts between perception and perception control conditions for MX.

\begin{tabular}{|c|c|c|c|c|c|}
\hline Anatomical area & Cluster size $k$ & Voxel $t$ & $X$ & Y & $Z$ \\
\hline \multicolumn{6}{|l|}{ Frontal lobes: } \\
\hline L inferior frontal gyrus & 354 & 4.69 & -58 & 22 & 32 \\
\hline L inferior frontal gyrus & & 4.64 & -58 & 30 & 16 \\
\hline L inferior frontal gyrus & & 4.33 & -42 & 28 & 20 \\
\hline $\mathrm{R}$ inferior frontal gyrus & 133 & 3.95 & 44 & 18 & 26 \\
\hline $\mathrm{R}$ inferior frontal gyrus & & 3.85 & 58 & 18 & 38 \\
\hline $\mathrm{R}$ inferior frontal gyrus & & 3.65 & 50 & 16 & 32 \\
\hline $\mathrm{R}$ inferior frontal gyrus & 23 & 3.65 & 56 & 42 & 12 \\
\hline \multicolumn{6}{|l|}{ Parietal lobes: } \\
\hline L precuneus & 38 & 3.66 & -4 & -54 & 34 \\
\hline L precuneus & 50 & 3.56 & -2 & -52 & 12 \\
\hline $\mathrm{R}$ precuneus & 24 & 3.33 & 12 & -48 & 64 \\
\hline $\mathrm{R}$ precuneus & 46 & 3.23 & 12 & -52 & 14 \\
\hline $\mathrm{R}$ precuneus & & 3.02 & 6 & -44 & 6 \\
\hline $\mathrm{R}$ precuneus & & 2.75 & 4 & -52 & 14 \\
\hline \multicolumn{6}{|l|}{ Temporal/occipital lobes: } \\
\hline L middle temporal gyrus & 176 & 7.47 & -66 & -6 & -16 \\
\hline L middle temporal gyrus & & 3.01 & -70 & -16 & -6 \\
\hline L middle temporal gyrus & 288 & 6.91 & -66 & -46 & -10 \\
\hline L middle temporal gyrus & & 5.45 & -70 & -30 & -10 \\
\hline L middle temporal gyrus & 135 & 4.22 & -40 & -66 & 18 \\
\hline $\mathrm{R}$ middle temporal gyrus & 400 & 5.46 & 62 & -62 & 8 \\
\hline R middle temporal gyrus & & 5.04 & 68 & -50 & 8 \\
\hline R middle temporal gyrus & & 3.89 & 52 & -52 & 10 \\
\hline $\mathrm{R}$ middle temporal gyrus & 71 & 4.81 & 52 & -36 & 0 \\
\hline R middle temporal gyrus & 28 & 3.52 & 58 & -8 & -22 \\
\hline L fusiform gyrus & 499 & 7.91 & -42 & -80 & -16 \\
\hline L inferior occipital gyrus & & 7.29 & -44 & -84 & -4 \\
\hline L fusiform gyrus & & 6.84 & -38 & -46 & -26 \\
\hline R fusiform gyrus & 36 & 4.33 & 30 & -6 & -44 \\
\hline R inferior occipital gyrus & 650 & 8.18 & 52 & -76 & -10 \\
\hline $\mathrm{R}$ inferior occipital gyrus & & 7.55 & 46 & -72 & -16 \\
\hline $\mathrm{R}$ fusiform gyrus & & 7.48 & 48 & -62 & -22 \\
\hline
\end{tabular}

Results of subject-level analysis for $\mathrm{MX}, \mathrm{df}=318$. Significant results reported as in Table 2. 

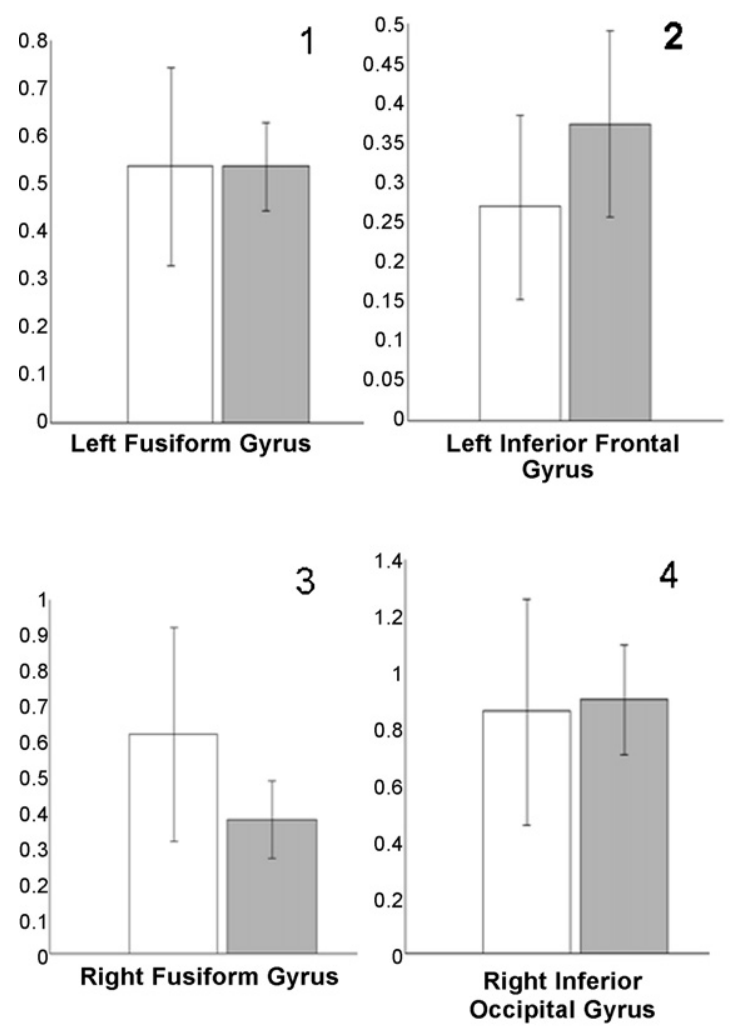
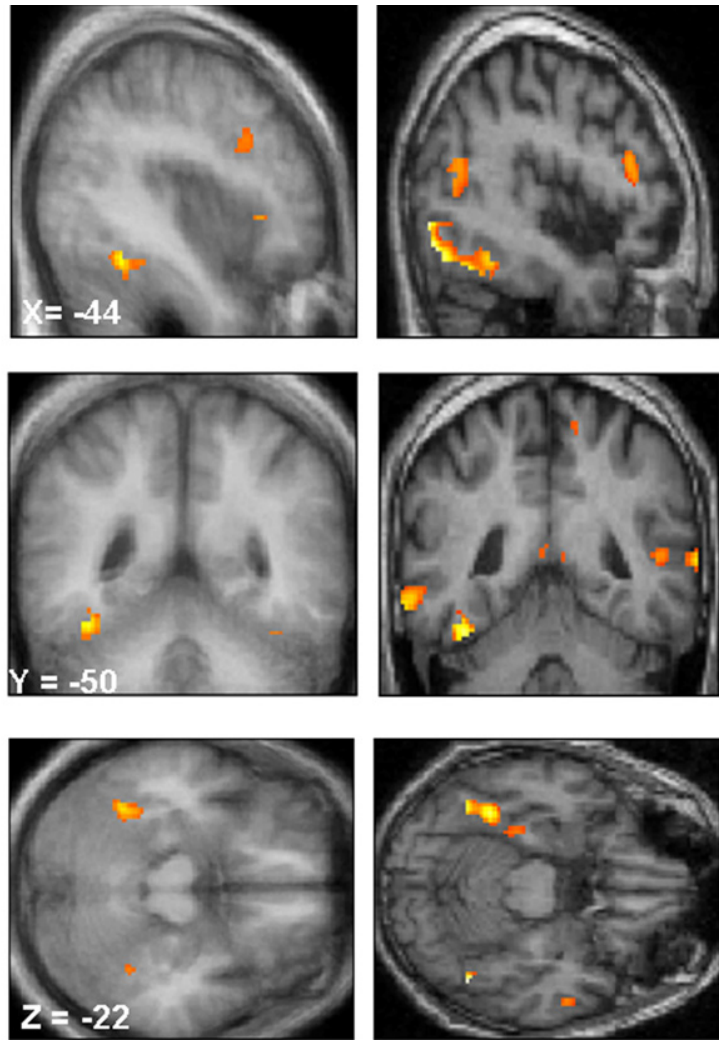

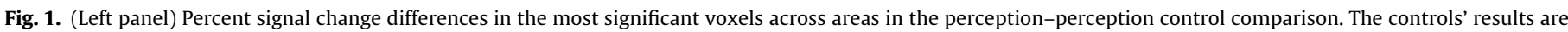

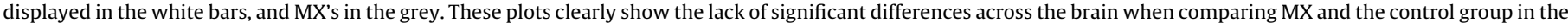

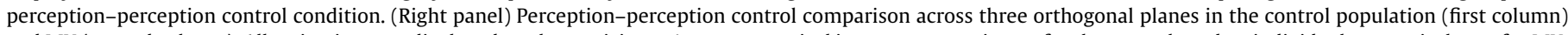

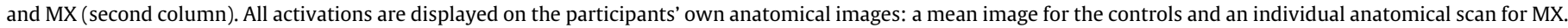
The left side of the brain is shown on the left side of the image.

to the mean session image to correct for subject motion, normalized to a standard brain template in the space defined by the Montreal Neurological Institute 152 brain average ("MNI space"), and spatially smoothed ( $8 \mathrm{~mm}$ Gaussian kernel). The data were filtered with a $240 \mathrm{~s}$ high-pass filter, and an AR(1)-model was used to account for serial correlation in the data. Each participant's T1-weighted structural image was co-registered to the mean functional image for each run, and normalized to MNI space using the functional runs' normalization parameters. After normalization, a mean structural image was created from the individual images of all normal participants.

Experimental effects were estimated using session design matrices modelling the hemodynamically convolved time-course of each condition (perception; perception control, imagery, and imagery control). The six movement parameters estimated during realignment were included as confounds. Linear contrasts of Perception vs. Perception Control and Imagery vs. Imagery Control were evaluated for each participant. The parameter estimates for each participant were subsequently entered into a second-level group analysis, comparing MX to the control population with a 2-sample $t$ test in which $t$ values were calculated for each voxel, treating interparticipant variation as random effect. When reporting results on the study controls in isolation, a 1-sample $t$ test was used.

We focused our analysis on cortical areas previously implicated in famous face perception and imagery by using a mask that included the inferior frontal gyrus, the anterior cingulate cortex, the superior and middle temporal gyri, the precuneus, the fusiform and inferior occipital gyri and the calcarine, all bilaterally (Haxby et al., 2000; Ishai, Ungerleider, \& Haxby, 2000; Ishai, Haxby, \& Ungerleider 2002). The mask was created in MNI space using the SPM extension WFU PickAtlas v2.4 (Maldjian et al., 2003) and the aal atlas (Tzourio-
Mazoyer et al., 2002). Clusters of 20 or more contiguous voxels with a voxel-level statistical significance of greater than $p<0.05$ (corrected for multiple comparisons across the mask volume using the false discovery rate-FDR; Genovese, Lazar, \& Nichols, 2002) were reported.

\subsection{Results}

In MX and control participants, face perception, in comparison to the perception control condition, activated areas anticipated from previous work including the inferior occipital and fusiform gyri (Tables 2 and 3, Fig. 1). Importantly, no significant differences were detected in brain activation for looking at famous faces between MX and control participants.

Face imagery, in comparison to the imagery control condition, activated a widespread network of frontal and posterior brain regions in control participants, including the fusiform gyrus and calcarine sulcus, in keeping with previous reports (Table 4). A similar network was activated during attempted visualisation in MX (Table 5). However, the critical comparison between MX and control participants in the imagery condition revealed notable differences. In particular, there was decreased activation for MX compared to controls in a predominantly posterior network of regions including bilateral fusiform gyri, superior temporal gyri/sulci, inferior occipital gyri and calcarine sulci (Table 6 and Fig. 2). The majority of these regions belong to the face perception 'core' network, and, as noted earlier, are activated during visual imagery in normal subjects. In contrast, there was greater activation for MX relative to control participants in predominantly anterior regions including the right anterior cingulate, bilateral inferior frontal gyri, and the precuneus (Table 7). 
Table 4

Cluster sizes and significant $t$ values for contrasts between imagery and imagery control conditions for control participants.

\begin{tabular}{|c|c|c|c|c|c|}
\hline Anatomical area & Cluster size $k$ & Voxel $t$ & $X$ & $Y$ & $Z$ \\
\hline \multicolumn{6}{|l|}{ Frontal lobes: } \\
\hline L inferior frontal gyrus & 518 & 9.89 & -36 & 18 & 32 \\
\hline L inferior frontal gyrus & & 5.74 & -36 & 44 & 12 \\
\hline L inferior frontal gyrus & & 5.63 & -32 & 32 & 8 \\
\hline $\mathrm{R}$ inferior frontal gyrus & 162 & 6.51 & 40 & 22 & 10 \\
\hline $\mathrm{R}$ inferior frontal gyrus & & 5.12 & 40 & 32 & 2 \\
\hline $\mathrm{R}$ inferior frontal gyrus & & 5.00 & 32 & 30 & 2 \\
\hline $\mathrm{R}$ inferior frontal gyrus & 216 & 5.72 & 32 & 22 & 28 \\
\hline $\mathrm{R}$ inferior frontal gyrus & & 5.44 & 32 & 14 & 32 \\
\hline $\mathrm{R}$ inferior frontal gyrus & & 4.87 & 36 & 4 & 28 \\
\hline \multicolumn{6}{|l|}{ Parietal lobes: } \\
\hline L precuneus & 51 & 7.62 & -10 & -46 & 14 \\
\hline L precuneus & & 6.74 & -8 & -40 & 6 \\
\hline \multicolumn{6}{|l|}{ Temporal lobes: } \\
\hline L superior temporal sulcus & 35 & 5.61 & -40 & -52 & 10 \\
\hline L superior temporal sulcus & & 5.50 & -40 & -54 & 20 \\
\hline L middle temporal gyrus & 153 & 5.58 & -54 & -26 & -10 \\
\hline L middle temporal gyrus & & 5.39 & -60 & -34 & -12 \\
\hline L middle temporal gyrus & & 5.06 & -66 & -50 & 2 \\
\hline $\mathrm{R}$ middle temporal gyrus & 31 & 4.79 & 68 & -22 & -14 \\
\hline $\mathrm{R}$ fusiform gyrus & 32 & 5.46 & 44 & -24 & -18 \\
\hline \multicolumn{6}{|l|}{ Occipital lobes: } \\
\hline L calcarine & 47 & 4.97 & -12 & -76 & 6 \\
\hline $\mathrm{R}$ calcarine & 21 & 6.41 & 22 & -98 & 2 \\
\hline
\end{tabular}

Results of group-level analysis, 1 -sample $t, \mathrm{df}=9$. Significant results reported as in Table 2.

\subsection{Discussion of fMRI results}

The same neuroanatomical network was activated in MX and controls during the visual perception of faces. However, the pattern of activation in MX was very different from that in controls when asked to generate images of faces.

The functional imaging results are in keeping with MX's subjective report of loss of visual imagery. Rather than activating the posterior visual network employed by the healthy control participants in the imagery condition, MX utilises a predominately frontal network that includes the inferior frontal and anterior cingulate gyri. These functionally diverse areas are activated persistently by a wide variety of executive tasks (see Duncan \& Owen, 2000 for a review). The inferior frontal gyrus has been associated with selection processes and semantic retrieval (Moss et al., 2005): its activation could reflect an attempt to perform the task in a non visual way. The supracallosal anterior cingulate is implicated in error prediction (Brown \& Braver, 2005): given that MX reports an inability to perform the task it is reasonable to assume that he did not expect to visualise successfully, supporting an interpretation of the cingulate activation in terms of performance monitoring. This area also is sensitive to task difficulty (Paus, Koski, Caramanos \& Westbury, 1998), which could be of relevance, since MX is likely to find this task effortful. However, this area also coincides with a region identified as relevant specifically to visual tasks (Paus, 2001). The most plausible explanation in keeping with the rest of the data is that the relatively increased activation in MX reflects his difficulty in performing the task and his search for alternative strategies, as the activated areas are highly connected and believed to be involved in a strategic and regulatory network (Bush, Luu \& Posner, 2000). His normal or near normal performance on imagery tasks attests to the success of these strategies.

\section{Experimental behavioural testing}

MX reports the loss of the experience of visual imagery, and fails to activate a range of posterior brain regions during attempted
Table 5

Cluster sizes and significant $t$ values for contrasts between imagery and imagery control conditions for MX.

\begin{tabular}{|c|c|c|c|c|c|}
\hline Anatomical area & Cluster size $k$ & Voxel $t$ & $X$ & $Y$ & $Z$ \\
\hline \multicolumn{6}{|l|}{ Frontal/limbic lobes: } \\
\hline L anterior cingulate & 1682 & 7.01 & 0 & 44 & 14 \\
\hline L anterior cingulate & & 5.69 & 0 & 32 & 30 \\
\hline $\mathrm{R}$ anterior cingulate & & 6.41 & 2 & 44 & 6 \\
\hline L inferior frontal gyrus & 1959 & 6.69 & -38 & 18 & 34 \\
\hline L inferior frontal gyrus & & 6.07 & -54 & 22 & 20 \\
\hline L inferior frontal gyrus & & 5.58 & -44 & 28 & 28 \\
\hline $\mathrm{R}$ inferior frontal gyrus & 2432 & 5.87 & 50 & 32 & 14 \\
\hline $\mathrm{R}$ inferior frontal gyrus & & 5.85 & 54 & 22 & 12 \\
\hline $\mathrm{R}$ inferior frontal gyrus & & 5.71 & 46 & 12 & 38 \\
\hline \multicolumn{6}{|l|}{ Parietal lobes: } \\
\hline L precuneus & 2933 & 7.01 & -2 & -62 & 66 \\
\hline L precuneus & & 7.00 & -12 & -56 & 42 \\
\hline $\mathrm{R}$ precuneus & & 6.48 & 8 & -38 & 52 \\
\hline L precuneus & 137 & 4.50 & -6 & -48 & 12 \\
\hline L precuneus & & 3.50 & -10 & -40 & 6 \\
\hline L precuneus & & 3.19 & -18 & -44 & 2 \\
\hline $\mathrm{R}$ precuneus & 60 & 4.29 & 10 & -38 & 6 \\
\hline \multicolumn{6}{|l|}{ Temporal lobes: } \\
\hline R superior temporal gyrus & & 5.10 & 66 & -38 & 22 \\
\hline L middle temporal gyrus & 1635 & 7.33 & -70 & -26 & -18 \\
\hline L middle temporal gyrus & & 7.16 & -56 & -18 & -24 \\
\hline L middle temporal gyrus & & 5.01 & -62 & -46 & -10 \\
\hline L middle temporal gyrus & 29 & 2.75 & -58 & -62 & 10 \\
\hline $\mathrm{R}$ middle temporal gyrus & 1281 & 7.56 & 58 & 0 & -30 \\
\hline $\mathrm{R}$ middle temporal gyrus & & 6.37 & 60 & -10 & -26 \\
\hline $\mathrm{R}$ middle temporal gyrus & & 5.81 & 72 & -24 & -20 \\
\hline $\mathrm{R}$ middle temporal gyrus & 1163 & 5.35 & 50 & -56 & 2 \\
\hline $\mathrm{R}$ middle temporal gyrus & & 4.55 & 56 & -58 & 12 \\
\hline L fusiform gyrus & 435 & 5.34 & -32 & -10 & -26 \\
\hline L fusiform gyrus & & 5.05 & -56 & -68 & -16 \\
\hline L fusiform gyrus & & 4.90 & -38 & -16 & -34 \\
\hline R fusiform gyrus & 406 & 5.71 & 48 & -30 & -18 \\
\hline R fusiform gyrus & & 5.36 & 48 & -34 & -28 \\
\hline R fusiform gyrus & & 5.33 & 40 & -20 & -32 \\
\hline \multicolumn{6}{|l|}{ Occipital lobes: } \\
\hline L calcarine & 84 & 4.41 & -4 & -86 & -14 \\
\hline L calcarine & & 3.52 & -8 & -92 & -8 \\
\hline L calcarine & & 2.61 & -10 & -100 & -14 \\
\hline $\mathrm{R}$ inferior occipital gyrus & 24 & 3.17 & 48 & -66 & -16 \\
\hline
\end{tabular}

Results of subject-level analysis for MX, $\mathrm{df}=318$. Significant results reported as in Table 2.

imagery. However, he performs well on standard imagery tests. From the fMRI study, it appeared that he was using a different network from controls in performing the imagery task. Here, we consider whether the different activation pattern observed might reflect the use of alternative cognitive strategies. To this end, we used two further, behavioural, tests namely versions of the matrix and verbal tasks devised by Brooks (1967), and a mental rotation task (Shepard \& Metzler, 1971).

The Brooks' (1967) tasks involve presenting participants with a series of sentences that they are required to encode either as a spatial image or as a verbal sequence. Based on versions of these tasks used by Salway and Logie (1995), MX's span on the spatial task was 4.33 , and on the verbal task it was 6.33 . In experiments with highly educated healthy controls, performance on the spatial task (typically 8-10) is always greater than performance on the verbal task (typically 5-7) (e.g. Baddeley, Grant, Wight and Thomson, 1975; Brooks, 1967; Quinn \& Ralston, 1986; Salway \& Logie, 1995).

Given the rather unusual pattern of performance in MX for the two Brooks' spans, in particular the relatively poor performance on the spatial task, a follow up testing session 4 weeks later used secondary task procedures to investigate whether he might be using alternative strategies to perform the visuo-spatial version of the task. MX performed the visuo-spatial task under three conditions. First was a control condition in which the task was performed 
Table 6

Cluster sizes and significant $t$ values for contrasts between imagery and imagery control conditions for MX vs. control participants (controls $>$ MX).

\begin{tabular}{|c|c|c|c|c|c|}
\hline Anatomical area & Cluster size $k$ & Voxel $t$ & $X$ & $Y$ & $Z$ \\
\hline \multicolumn{6}{|l|}{ Parietal lobes: } \\
\hline $\mathrm{R}$ precuneus & 48 & 5.38 & 16 & -58 & 42 \\
\hline \multicolumn{6}{|l|}{ Temporal lobes: } \\
\hline R superior temporal gyrus & 22 & 4.49 & 56 & -26 & 14 \\
\hline L superior temporal sulcus & 283 & 11.62 & -48 & -30 & 12 \\
\hline L superior temporal sulcus & & 6.30 & -50 & -40 & 12 \\
\hline L superior temporal sulcus & & 3.78 & -48 & -42 & 2 \\
\hline L middle temporal gyrus & 448 & 16.54 & -46 & -16 & -14 \\
\hline L middle temporal gyrus & & 14.11 & -46 & -8 & -18 \\
\hline L middle temporal gyrus & & 13.60 & -40 & 0 & -30 \\
\hline L middle temporal gyrus & 37 & 5.60 & -62 & -6 & -8 \\
\hline L middle temporal gyrus & & 5.24 & -60 & 4 & -8 \\
\hline R superior temporal sulcus & 467 & 14.04 & 44 & -20 & 0 \\
\hline R middle temporal gyrus & & 11.04 & 46 & -4 & -30 \\
\hline R middle temporal gyrus & & 9.83 & 48 & -12 & -12 \\
\hline L fusiform gyrus & 516 & 27.80 & -16 & -42 & -12 \\
\hline L fusiform gyrus & & 16.75 & -28 & -56 & -16 \\
\hline L fusiform gyrus & & 13.02 & -20 & -32 & -20 \\
\hline $\mathrm{R}$ fusiform gyrus & 31 & 15.32 & 38 & -2 & -32 \\
\hline R fusiform gyrus & 532 & 12.41 & 26 & -32 & -22 \\
\hline $\mathrm{R}$ fusiform gyrus & & 10.02 & 20 & -46 & -14 \\
\hline R fusiform gyrus & & 9.66 & 20 & -38 & -18 \\
\hline \multicolumn{6}{|l|}{ Occipital lobes: } \\
\hline L calcarine & & 3.83 & -2 & -62 & 8 \\
\hline $\mathrm{R}$ calcarine & 23 & 8.39 & 24 & -102 & 2 \\
\hline $\mathrm{R}$ calcarine & 230 & 8.29 & 2 & -76 & 6 \\
\hline R inferior occipital gyrus & 20 & 4.42 & 36 & -90 & -10 \\
\hline
\end{tabular}

Results of group-level analysis, 2-sample $t, \mathrm{df}=9$. Significant results reported as in Table 2 .

without any distractor tasks. Next, MX was required to suppress articulation by repeating aloud the word 'the' throughout presentation of the material for recall. Articulatory suppression typically reduces performance when participants are using verbal codes in short-term memory tasks (Murray, 1965; Salway \& Logie, 1995). In the third condition, MX was required to tap on the table in a figure of eight pattern throughout presentation. Previous studies have shown that highly educated healthy participants perform more poorly when the Brooks visuo-spatial task is combined with concurrent pattern tapping (Baddeley \& Lieberman, 1980; Salway \& Logie, 1995; Smyth \& Scholey, 1994). For the Brooks matrix (visuospatial) task, MX successfully recalled a mean of 6.8 items across ten trials in the control condition compared with the first testing session 4 weeks earlier when he could only recall sequences of 4 or 5 items reliably. The control performance was significantly higher $(p<0.01)$ than the mean recall of 4.7 items with articulatory suppression across ten trials, which in turn was significantly lower

Table 7

Cluster sizes and significant $t$ values for contrasts between imagery and imagery control conditions for MX vs. control participants (MX>controls).

\begin{tabular}{lllrrr}
\hline Anatomical area & Cluster size $k$ & Voxel $t$ & $X$ & $Y$ & $Z$ \\
\hline Frontal/limbic lobes: & & & & & \\
R anterior cingulate & 246 & 9.41 & 4 & 28 & 14 \\
R anterior cingulate & & 8.09 & 2 & 42 & 10 \\
R anterior cingulate & & 6.34 & 4 & 24 & 24 \\
L inferior frontal gyrus & 25 & 9.27 & -44 & 10 & 2 \\
R inferior frontal gyrus & 46 & 9.11 & 40 & 36 & 2 \\
Parietal lobes: & & & & & \\
L precuneus & 39 & 7.02 & -14 & -52 & 44 \\
Temporal lobes: & & & & & \\
R middle temporal gyrus & 32 & 7.25 & 48 & -70 & 20 \\
R middle temporal gyrus & 55 & 6.48 & 50 & -58 & 6 \\
\hline
\end{tabular}

Results of group-level analysis, 2-sample $t, \mathrm{df}=9$. Significant results reported as in Table 2. than the mean recall of 6.9 items across 10 trials when combined with pattern tapping. Pattern tapping and control conditions did not differ. The drop with articulatory suppression on the spatial task coupled with the lack of an effect of tapping is the opposite pattern to that found in previous studies with healthy participants. Taking the results across both test sessions, it appears that MX had great difficulty trying to encode the material with an impaired visuospatial system on the first test session. The fact that articulatory suppression disrupted performance levels on the second test session suggests that he had developed a much more effective verbal strategy for the spatial task when being retested a few weeks later.

Mental rotation is a widely used test for mental imagery (see review in Richardson, 1999). We tested MX and five right handed males age 60-65, matched on education with MX, who acted as controls. The Shepard and Metzler (1971) materials were used for assessing mental rotation. These involve pictures of 3D objects comprising 10 cubes joined in different configurations. ${ }^{3}$ Pairs of objects were presented on a computer screen with one item rotated within three-dimensional space relative to the other. The angle of rotation was varied between zero and 180 degrees in 20 degree steps. In half of the pairs, the objects were identical, in the other half the objects were different. For each pair the participant was asked to decide whether or not the two items were identical by pressing keys for 'same' and 'different' with the index finger of each hand. They were instructed to respond as quickly as possible while maintaining accuracy. There were 20 trials for each angle (10 same, 10 different), presented in a random order, giving 200 trials in total.

In typical experiments there is a linear relationship between angle of rotation between the items in each pair, and the time taken for each participant to make a correct decision: larger angles result in longer decision times. This is interpreted as suggesting that participants mentally rotate one or other item in the pair to form a mental image in which the two items are represented as being at the same angle, thus allowing a decision regarding whether they match. The larger the angle, the longer this mental rotation process takes, and therefore the longer will be the decision time just as would be the case if the physical objects were being rotated in space. Accuracy rates are normally high, and error response times are not included. Although older participants take more time to make a decision overall than younger people, the linear relationship remains clear (e.g. Band \& Kok, 2000; Dror \& Kosslyn, 1994). If participants are not using this form of mental imagery, then we might expect a much poorer relationship between angle of rotation and response time, for example a shallower slope or a non-linear function (see, e.g., Ditunno \& Mann, 1990).

All comparisons between MX and the five controls followed the procedure devised by Crawford and Howell (1998) and Crawford and Garthwaite $(2002,2004)$ for comparing a single case against a small group of healthy matched controls. From the mean correct response times, $\mathrm{MX}$ (mean $=8540 \mathrm{~ms}$ ) was overall slower than the controls ( $6168 \mathrm{~ms}, \mathrm{sd}=752$ ), and this was significant, $t=2.879$, $p<0.05$. MX appeared to have fewer errors (10) than controls ( mean $=26$ ), but this difference was not significant, $t=1.48, p>0.1$. However, what is of primary interest is whether MX shows the same relationship as the controls between response time and angle.

Mean data for MX and the five controls are shown in Fig. 3 for each angle of rotation. Regression analyses revealed significant linear and quadratic components to the functions for both MX and controls, however, the function for MX looks strikingly different. Using the Crawford and Garthwaite (2004) procedure for comparing slopes between a single case and a group of matched controls, the slopes for these data are significantly different, $t=9.686$,

\footnotetext{
3 Materials were obtained in digitized form from: http://titan.cog.brown.
} edu:8080/TarrLab/stimuli/novel-objects/shepard.zip/view. 

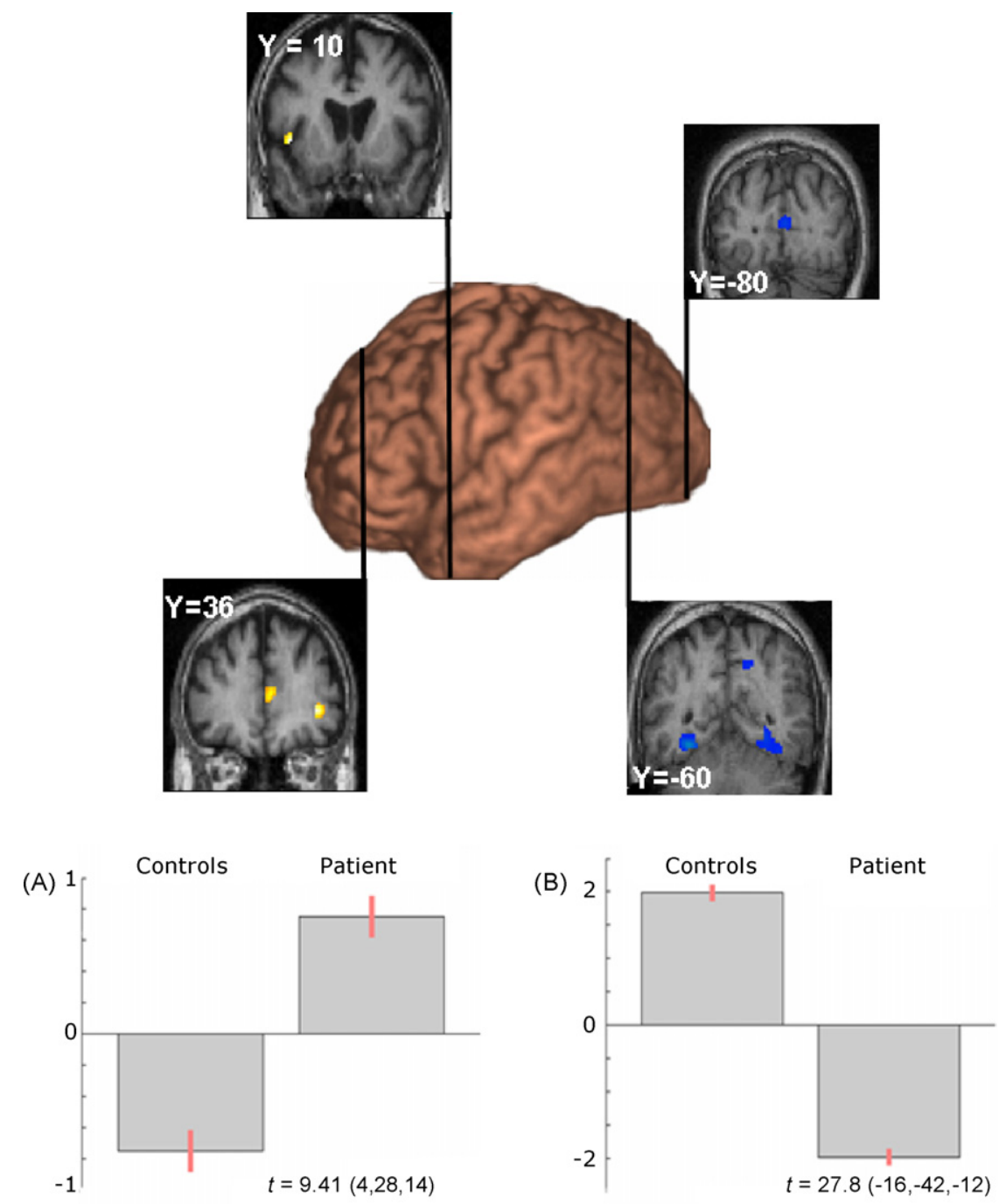

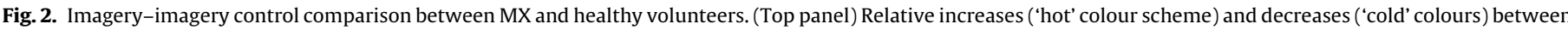

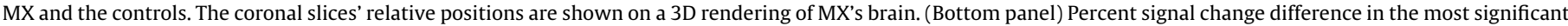
voxels for both relative increases (A, right anterior cingulate cortex) and decreases (B, left fusiform cortex) between MX and controls.

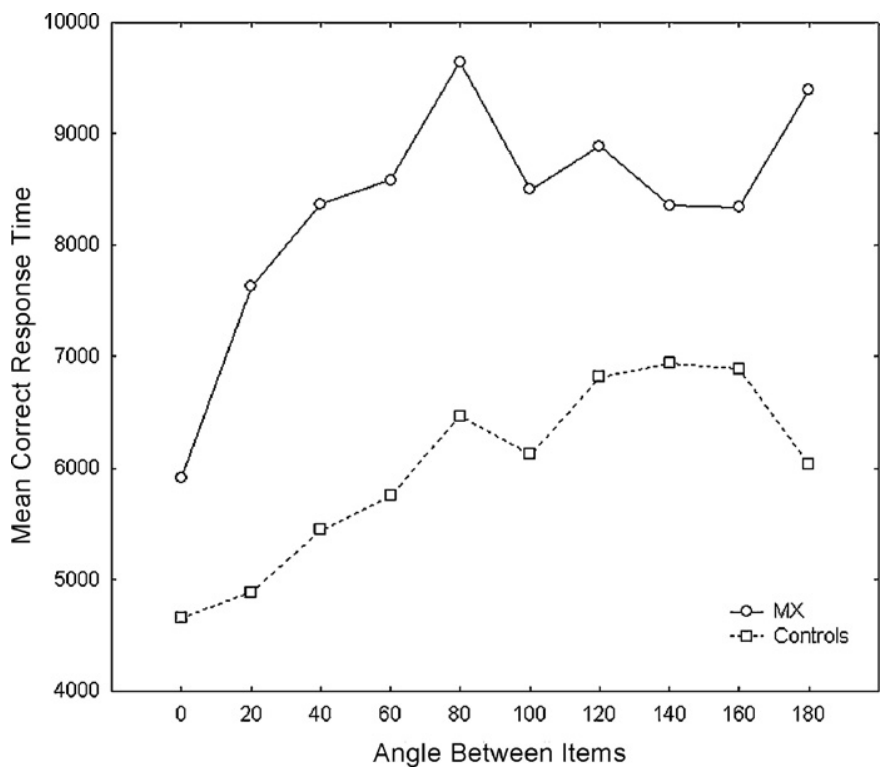

Fig. 3. Mean correct response time on mental rotation for MX and for five matched control participants. $p<0.001$; for $\operatorname{MX} \beta=0.241$, for controls $\beta=0.517$. This suggests that MX is using a different strategy from the control participants to perform the task, and this strategy clearly takes longer to accomplish. It is notable that, in the debriefing session, MX reported that he was attempting to match individual blocks and angles perceptually when making his decision.

\subsection{Discussion of experimental behavioural testing}

The psychometric results, and the overall performance levels for MX indicated that he was showing no cognitive impairment. However, there were suggestions from the Brooks' matrix test data that his performance during the first test session on the spatial imagery condition was poorer, but his performance on the verbal condition was similar to that normally found for people with his level of education and mental ability. On the subsequent testing session, he had clearly improved on the spatial imagery condition, and his performance was well within the range normally found in previous studies. However, his verbal performance had also improved, and was at the same level as he obtained for the spatial condition. Moreover, a verbal secondary task, but not a spatial secondary task disrupted his performance on remembering the matrix patterns. This is a very unusual pattern since in all previously published stud- 
ies of these tasks (e.g. Baddeley et al., 1975; Quinn \& Ralston, 1986; Salway \& Logie, 1995), well educated healthy participants typically perform more poorly with the verbal version than with the spatial imagery version, and are more sensitive to a spatial than to a verbal interference task. Therefore, it appeared that during the second testing session, MX learned to use a verbal strategy effectively to achieve normal levels of performance on the spatial matrix task, but that his poor performance on the first test session reflected impaired spatial abilities.

The results for mental rotation likewise show a rather unusual pattern. MX is slower than the matched controls, but his accuracy rate is higher. Crucially he shows a strikingly different relationship between response time and increasing angle than the controls.

Taken together, the data from the Brooks' tasks and from mental rotation point to MX using rather different strategies from control participants to achieve normal levels of performance, a conclusion that fits with MX's own report of how he was attempting the tasks. This suggests that alternative strategies are possible for tasks thought to rely on imagery. However, when those alternative strategies are being used, a rather different pattern of data emerges. This result is complementary to an analogous finding from the verbal memory domain in which participants have been shown to use an alternative strategy involving visual codes in retention of verbally based material that is typically assumed to be encoded phonologically (Logie, Della Sala, Laiacona, Chalmers \& Wynn, 1996; Logie, Della Sala, Wynn \& Baddeley, 2000; Saito, Logie, Morita \& Law, 2008).

\section{General discussion}

We report the case of a patient who abruptly lost the ability to generate visual images, both voluntarily and spontaneously during dreaming, who rates himself as experiencing almost no imagery on standard questionnaires, and yet performs at normal levels on standard tests of visual imagery and visual memory. His subjective report was corroborated by evidence from functional imaging showing that, while his brain activation on viewing famous faces were identical to that of controls, activation during attempted imagery was markedly different: posterior cortices were relatively hypo-activated while some frontal regions were relatively hyper-activated. We refer to this pattern of spared and impaired abilities as 'blind imagination'. Additional experimental behavioural tests suggested that MX was using alternative, nonstandard, strategies to achieve his normal performance in imagery tasks.

Reviewing the literature on acquired visual imagery impairments, Farah (1984) distinguished: (i) 'visual imagery generation deficits', causing impairment on measures of visual imagery without impairment on tests of perception; (ii) deficits of long-term visual memory, causing parallel impairments of recognition and imagery; (iii) 'inspection process deficits', reflecting a lower level visual disorder impairing description, recognition and imagery. Farah's classification rests on a theoretical model of imagery which proposes that perception and imagery share a common 'visual buffer': in perception, this is activated by incoming sensory input, while, in imagery, representations in long-term visual memory are activated 'top-down' and transferred into the buffer. Within this framework, our case can be regarded an exceptionally pure example of a visual imagery generation deficit, with - unusually - little or no apparent impact on performance levels in imagery tests, and intact perception. However, the underlying assumptions of Farah's classification have been questioned by some recent cases. In particular, while it is agreed that parallel impairments of perception and imagery sometimes occur, the sparing of imagery in some patients with cortically based perceptual impairments poses a challenge for the framework, as such cases appear to involve preservation of imagery in the absence of the visual buffer (Bartolomeo et al., 1998; Behrmann et al., 1994; Dulin, Hatwell, Pylyshyn \& Chokron, 2008). This indicates a lack of overlap between perception and imagery that is not consistent with Farah's hierarchical model. On the other hand, models that do not assume a common buffer for perception and imagery can account for both patients showing a pure perceptual deficit and for case MX (for recent discussion see Baddeley \& Andrade, 2000; van der Meulen, Logie \& Della Sala, 2008; Logie \& van der Meulen, 2009). We further place the functional imaging findings in MX's case in the context of work on the neural basis of visual imagery below.

MX's normal performance on 'imagery tasks' in the absence of any associated visual experience might be interpreted as suggesting that the experience of visual imagery is not needed in order to perform imagery tasks. This might be seen as consistent with the view that performance on imagery tasks is primarily based on propositional processes and tacit knowledge (Pylyshyn, 1973, 2002), in contrast with the views championed by Paivio (1971) and by Kosslyn (e.g. Kosslyn et al., 2006) who argue that the ability to generate a mental image serves an important functional role in cognition. Our results may offer a possible resolution to this debate by pointing to the flexibility with which participants can adopt different strategies for performing the same task. In particular, healthy participants may adopt the use of a mental imagery strategy or a propositional strategy depending on the task and the effectiveness with which they can use each strategy. For example, mental imagery might be useful when tacit knowledge is insufficient. When MX attempts to use imagery his task performance is rather poor, as was shown in the first test session with the Brooks matrices. When he appeared to adopt different strategies that relied on verbal coding, his performance was in the normal range. A similar conclusion can be drawn from the mental rotation data where MX performed within the normal range for accuracy, but showed a much less clear relationship between response time and angle of rotation than did the matched controls. This indicated that he was not using mental rotation, and his post-experimental verbal reports confirmed that he had used a perceptual matching strategy. The use of non-imagery based strategies to solve tasks for which imagery would normally be used has been reported in other contexts. For example behavioural evidence suggests that the characteristic impairment in block design performance seen in Williams' syndrome arises from an inability to use visual imagery with a resulting reliance on a less efficient manual strategy (Farran, Jarrold \& Gathercole, 2001).

The fMRI results corroborate MX's subjective report of his symptoms and the rather unusual patterns of performance observed for the Brooks' matrix task and for mental rotation. He showed exactly the same pattern of activation as the controls when the perception condition was contrasted with the perceptual control, including the expected activation of the fusiform gyrus associated with face processing (e.g. Haxby, Hoffman \& Gobbini, 2000). When the imagery condition was contrasted with the imagery control, the control patients showed the expected activation in the fusiform area that had also been found by Ishai et al. (2002). However, MX showed decreased activation in the fusiform and related areas linked with face processing, but showed greater activation than controls in predominantly anterior regions. Thus the imagery condition resulted in very different patterns of brain activation in MX and in controls, pointing to a perturbation of function in MX, consistent with the behavioural data pattern and his subjective report. The relative increase in prefrontal activation in MX during attempted visual imagery may reflect greater cognitive effort, or possibly the use by MX of alternative strategies using functionally intact neuroanatomical networks that are rarely if ever used by healthy participants when performing tasks thought to require visual imagery. 
The underlying neurological cause of MX's striking inability to experience mental imagery in the face of normal performance on tests of visual memory and visual imagery is unclear, but recent studies of the neural system subserving visual imagery suggests a possible mechanism. During perception the visual system is driven by incoming stimuli, 'bottom up'. During imagery there is evidence that areas of the visual brain engaged by perception are activated 'top-down' by a number of fronto-parietal regions involved in executive and attentional control (Goebel, KhorramSefat, Muckli, Hacker, \& Singer, 1998; Ishai et al., 2000). There is evidence from dynamic causal modelling for content-related connections between prefrontal cortex and extrastriate cortex during imagery, and content-unrelated connections between parietal and extrastriate cortex during both perception and imagery (Mechelli, Price, Friston, \& Ishai, 2004). In the light of this evidence the simplest neurological explanation for the dissociation between the preservation of perception and absence of imagery in MX is structural or functional disconnection between anterior regions required for imagery generation and the posterior regions which support the content of both perception and imagery. The clinical history suggests that a subtle ischaemic event at the time of MX's coronary angioplasty, probably affecting the right hemisphere, is the likeliest cause for such a disconnection. Focal lesions have been shown to exert selective and dissociable effects on imagery processing in other contexts (Sirigu et al., 1996). This explanation predicts the possibility the MX might show impairment of perceptual processes requiring a high degree of top-down control, together with evidence of disconnectivity between anterior and posterior brain regions. Given the subjective nature of the loss of voluntary imagery, we intend to use dynamic causal modeling to undertake the crucial test of this prediction in future work. The initial loss and subsequent recovery of dreaming in MX, while voluntary imagery remained impaired, suggests that these two forms of imagery involve partially but incompletely overlapping neural networks, which is plausible in both neurological and cognitive terms.

We have proposed that MX's preserved performance on tests of visual imagery is likely to be facilitated by the use of alternative non-visual strategies. There is, in principle, an alternative possibility-that MX's 'blind imagination' depends on the processing of intrinsically visual representations that no longer enter consciousness. We consider this less likely than an explanation in terms of alternative strategies given the evidence from experimental behavioural testing that MX's performance on imagery tasks differs qualitatively from performance in normals.

The case study of MX suggests four general conclusions. (i) First, as implied by the preceding discussion, there is an important distinction between the representation of visual information and the experience of visualisation that has been somewhat neglected in the literature: successful performance on standard tests of visual imagery does not always require the experience of visual imagery. (ii) This implies that, second, studies of visual imagery deficits should address both subjective and objective aspects of imagery. While some studies have explicitly reported the presence or absence of imagery (Servos \& Goodale, 1995; Bartolomeo et al., 1998), others have not made this explicit (Behrmann et al., 1994; Shuren, Maher \& Heilman, 1996), possibly assuming that success or failure on tests of visual imagery imply the presence or absence of subjective visual imagery: the present case calls this assumption into question. (iii) Third, the fMRI findings in this case add to the evidence that activation of posterior visual cortices is required for the experience of visual imagery (Ishai et al., 2000) but not for the performance of imagery tasks. (iv) Lastly, the findings demonstrate the value of functional imaging in revealing the use of alternative strategies when performing cognitive tasks.

\section{Acknowledgements}

We wish to thank Dr. Stephen Darling who helped us collecting the data on the Mental Rotation task, and Dr Lisa Archibald for assistance with collecting data on control participants in the fMRI simulator. We also thank Prof Ian Marshall for advice regarding the medical physics of the fMRI experiment, and Dr Alumit Ishai for helpful discussions and for assistance with preparing stimuli. We are grateful for the detailed and helpful comments of two anonymous reviewers. A. Zeman was partly supported by a Health Foundation mid-career award. S. Della Sala and R.H. Logie's work was partly funded by grant no. CZB/4/346 awarded by the Scottish Chief Scientist Office (CSO) for which V.E. Gountouna was a research fellow. Finally, we are very grateful to MX for participating in the experiments.

All study procedures were approved by the research ethics committee of UK National Health Service Ethical Committee (Lothian).

\section{Appendix A.}

\begin{tabular}{|c|c|c|}
\hline \multicolumn{3}{|l|}{ Example questions from famous face feature test } \\
\hline \multicolumn{3}{|l|}{ Tony Blair } \\
\hline Does he have large ears? & Answer: & Yes \\
\hline Does he have a moustache? & & No \\
\hline Does he have a receding chin? & & No \\
\hline Does he have a full head of hair? & & No \\
\hline Does he have a prominent crease beneath his cheeks? & & Yes \\
\hline Does he have light coloured eyes? & & Yes \\
\hline \multicolumn{3}{|l|}{ Example questions from facial expression feature test } \\
\hline \multicolumn{3}{|l|}{ Think of a face with a fearful expression-does it have: } \\
\hline Lips pursed? & Answer: & No \\
\hline Wide open eyes? & & Yes \\
\hline Corner of the mouth raised? & & No \\
\hline A wrinkled nose? & & No \\
\hline A furrowed brow? & & Yes \\
\hline Raised eyebrows? & & Yes \\
\hline
\end{tabular}

\section{References}

Ahmed, S., Arnold, R., Thompson, S. A., Graham, K. S., \& Hodges, J. R. (2008). Naming of objects, faces and buildings in mild cognitive impairment. Cortex, 44, 746-752.

Baddeley, A. D., \& Andrade, J. (2000). Working memory and the vividness of imagery. Journal of Experimental Psychology: General, 129, 126-145.

Baddeley, A. D., \& Lieberman, K. (1980). Spatial working memory. In R. S. Nickerson (Ed.), Attention and performance VIII (pp. 521-539). Hillsdale, NJ: Erlbaum.

Baddeley, A. D., Grant, S., Wight, E., \& Thomson, N. (1975). Imagery and visual working memory. In P. M. A. Rabbitt, \& S. Dornic (Eds.), Attention and performance $V$ (pp. 205-217). London: Academic Press.

Band, G. P., \& Kok, A. (2000). Age effects on response monitoring in a mental-rotation task. Biological Psychology, 51, 201-221.

Bartolomeo, P. (2002). The relationship between visual perception and visual mental imagery: A reappraisal of the neuropsychological evidence. Cortex, 38, 357-378.

Bartolomeo, P. (2008). The neural correlates of visual mental imagery: An ongoing debate. Cortex, 44, 107-108.

Bartolomeo, P., Bachoud-Lévi, A. C., De Gelder, B., Denes, G., Dalla Barba, G., Brugières, P., et al. (1998). Multiple-domain dissociation between impaired visual perception and preserved mental imagery in a patient with bilateral extrastriate lesions. Neuropsychologia, 36, 239-249.

Behrmann, M., Moscovitch, M., \& Winocur, G. (1994). Intact mental imagery and impaired visual perception: Dissociable processes in a patient with visua agnosia. Journal of Experimental Psychology: HPP, 20, 1068-1087.

Beschin, N., Cocchini, G., Della Sala, S., \& Logie, R. H. (1997). What the eyes perceive, the brain ignores: A case of pure unilateral representational neglect. Cortex, 33, $3-26$.

Botez, M. I., Olivier, M., Vézina, J. L., Botez, T., \& Kaufman, B. (1985). Defective revisualization: Dissociation between cognitive and imagistic thought case report and short review of the literature. Cortex, 21, 375-389.

Brain, R. (1954). Loss of visualization. Proceedings of the Royal Society of Medicine, 47, 288-290.

Brooks, L. R. (1967). The suppression of visualization by reading. Quarterly Journal of Experimental Psychology, 19, 289-299.

Brown, J. W., \& Braver, T. S. (2005). Learned predictions of error likelihood in the anterior cingulate cortex. Science, 307, 1118-1121.

Bush, G., Luu, P., \& Posner, M. I. (2000). Cognitive and emotional influences in anterior cingulate cortex. Trends in Cognitive Sciences, 4, 215-222. 
Charcot, J.-M., \& Bernard, D. (1883). Un cas de suppression brusque et isolée de la vision mentale des signes et des objects (formes et couleurs). Le Progrès Médicale, $11,568-571$.

Crawford, J. R., \& Garthwaite, P. H. (2002). Investigation of the single case in neuropsychology: Confidence limits on the abnormality of test scores and test score differences. Neuropsychologia, 40, 1196-1208.

Crawford, J. R., \& Garthwaite, P. H. (2004). Statistical methods for single-case research: Comparing the slope of a patient's regression line with the slopes of a control sample. Cortex, 40, 533-548.

Crawford, J. R., \& Howell, D. C. (1998). Comparing an individual's test score against norms derived from small samples. Clinical Neuropsychology, 12, 482486.

Ditunno, P. L., \& Mann, V. A. (1990). Right hemisphere specialization for mental rotation in normals and brain damaged subjects. Cortex, 26, 177-188.

Dror, I. E., \& Kosslyn, S. M. (1994). Mental imagery and aging. Psychology and Aging, 9, 90-102.

Dulin, D., Hatwell, Y., Pylyhshyn, Z., \& Chokron, S. (2008). Effects of peripheral and central visual impairment on mental imagery capacity. Neuroscience and Biobehavioural Reviews, 32, 1396-1408.

Duncan, J., \& Owen, A. (2000). Common regions of the human frontal lobe recruited by diverse cognitive demands. Trends in Neurosciences, 23, 475-483.

Eddy, J. K., \& Glass, A. L. (1981). Reading and listening to high and low imagery sentences. Journal of Verbal Learning \& Verbal Behavior, 20, 333-345.

Farah, M. J. (1984). The neurological basis of mental imagery: A componential analysis. Cognition, 18, 245-272.

Farran, E., Jarrold, C., \& Gathercole, S. E. (2001). Block design performance in the Williams syndrome phenotype: A problem with mental imagery? Journal of Clinical Psychology and Psychiatry, 42, 719-728.

Genovese, C. R., Lazar, N. A., \& Nichols, T. (2002). Thresholding of statistical maps in functional neuroimaging using the false discovery rate. Neuroimage, 15, $870-878$.

Goebel, R., Khorram-Sefat, D., Muckli, L., Hacker, H., \& Singer, W. (1998). The constructive nature of vision: Direct evidence from functional magnetic imaging studies of apparent motion and motion imagery. European Journal of Neuroscience, 10, 1563-1573.

Guariglia, C., Padovani, A., Pantano, P., \& Pizzamiglio, L. (1993). Unilateral neglect restricted to visual imagery. Nature, 364, 235-237.

Haxby, J. V., Hoffman, E. A., \& Gobbini, M. I. (2000). The distributed human neural system for face perception. Trends in Cognitive Sciences, 4, 223-233.

Ishai, A., Ungerleider, L. G., \& Haxby, J. V. (2000). Distributed neural systems for the generation of visual images. Neuron, 28, 979-990.

Ishai, A., Haxby, J. V., \& Ungerleider, L. G. (2002). Visual imagery of famous faces: Effects of memory and attention revealed by fMRI. Neuroimage, 17, 17291741.

Kaski, D. (2002). Revision: Is visual perception a requisite for visual imagery? Perception, 31, 717-731.

Kopelman, M. D., Wilson, B. A., \& Baddeley, A. D. (1990). The autobiographical memory interview. Bury St Edmunds: Thames Valley Test Company.

Kosslyn, S. M., Thompson, W. L., \& Ganis, G. (2006). The case for mental imagery. New York: Oxford University Press.

Logie, R. H., \& van der Meulen, M. (2009). Fragmenting and integrating visuo-spatial working memory. In J. R. Brockmole (Ed.), Representing the visual world in memory (pp. 1-32). Hove, UK: Psychology Press.

Logie, R. H., Della Sala, S., Laiacona, M., Chalmers, P., \& Wynn, V. (1996). Group aggregates and individual reliability: The case of verbal short-term memory. Memory and Cognition, 24, 305-321.

Logie, R. H., Della Sala, S., Wynn, V., \& Baddeley, A. D. (2000). Visual similarity effects in immediate verbal serial recall. Quarterly Journal of Experimental Psychology, $53 A, 626-646$.

Maldjian, J. A., Laurienti, P. J., Burdette, J. B., \& Kraft, R. A. (2003). An automated method for neuroanatomic and cytoarchitectonic atlas-based interrogation of fMRI data sets. Neuroimage, 19, 1233-1239.

Marks, D. F. (1973). Visual imagery differences in the recall of pictures. British Journal of Psychology, 64, 17-24.

Mazard, A., Mazoyer, B., Etard, O., Tzourio-Mazoyer, N., Kosslyn, S. M., \& Mellet, E. (2002). Impact of fMRI acoustic noise on the functional anatomy of visual mental imagery. Journal of Cognitive Neuroscience, 14, 172-186.

McKelvie, S. J. (1995). The VVIQ as a psychometric test of individual differences in visual imagery vividness: A critical quantitative review and a plea for direction. Journal of Mental Imagery, 3-4, 1-106.
Mechelli, A., Price, C. J., Friston, K. J., \& Ishai, A. (2004). Where bottom-up meets topdown: Neuronal interactions during perception and imagery. Cerebral Cortex, $14,1256-1265$.

Moro, V., Berlucchi, G., Lerch, J., Tomaiuolo, F., \& Aglioti, S. M. (2008). Selective deficit of mental visual imagery with intact primary visual cortex and visual perception. Cortex, 44, 109-118.

Moss, H. E., Abdallah, S., Fletcher, P., Bright, P., Pilgrim, L., Acres, K., et al. (2005). Selecting among competing alternatives: Selection and retrieval in the left inferior frontal gyrus. Cerebral Cortex, 15, 1723-1735.

Murray, D. J. (1965). Vocalization-at-presentation, with varying presentation rates. Quarterly Journal of Experimental Psychology, 17, 47-56.

Nelson, H. (1976). A modified card sorting test sensitive to frontal lobe defects. Cortex, 12, 313-324.

Paivio, A. (1971). Imagery and verbal processes. New York: Holt, Rinehart and Winston.

Paus, T. (2001). Primate anterior cingulate cortex: Where motor control, drive and cognition interface. Nature Reviews Neuroscience, 2, 417-424.

Paus, T., Koski, L., Caramanos, Z., \& Westbury, C. (1998). Regional differences in the effects of task difficulty and motor output on blood flow response in the human anterior cingulate cortex: A review of 107 PET activation studies. Neuroreport, 9, R37-R47.

Pylyshyn, Z. W. (1973). What the mind's eye tells the mind's brain: A critique of mental imagery. Psychological Bulletin, 80, 1-24.

Pylyshyn, Z. W. (2002). Mental imagery: In search of a theory. Behavioral \& Brain Sciences, 25, 157-238.

Quinn, J. G., \& Ralston, G. E. (1986). Movement and attention in visual working memory. Quarterly Journal of Experimental Psychology, 38A, 689-703.

Ratcliff, G. (1979). Spatial thought, mental rotation and the right cerebral hemisphere. Neuropsychologia, 17, 49-54.

Reisberg, D., Pearson, D. G., \& Kosslyn, S. M. (2003). Intuitions and introspections about imagery: The role of imagery experience in shaping an investigator's theoretical views. Applied Cognitive Psychology, 17, 147-160.

Richardson, J. T. E. (1999). Imagery. Hove: Psychology Press.

Saito, S., Logie, R. H., Morita, A., \& Law, A. (2008). Visual and phonological similarity effects in verbal immediate serial recall: A test with kanji materials. Journal of Memory and Language, 59, 1-17.

Salway, A. F., \& Logie, R. H. (1995). Visuospatial working memory, movement control and executive demands. British Journal of Psychology, 86, 253-269.

Servos, P., \& Goodale, M. A. (1995). Preserved visual imagery in visual form agnosia. Neuropsychologia, 33, 1383-1394.

Shepard, R. N., \& Metzler, J. (1971). Mental rotation of three-dimensional objects. Science, 171, 701-703.

Shuren, J. E., Maher, L. M., \& Heilman, K. M. (1996). The role of visual imagery in spelling. Brain \& Language, 52, 365-372.

Sirigu, A., Duhamel, J.-R., Cohen, L., Pillon, B., Dubois, B., \& Agid, Y.(1996). The mental representation of hand movements after parietal cortex damage. Science, 273, 1564-1568.

Smyth, M. M., \& Scholey, K. A. (1994). Interference in immediate spatial memory. Memory \& Cognition, 22, 1-13.

Stroop, J. R. (1935). Studies of interference in serial verbal reactions. Journal of Experimental Psychology, 18, 643-662.

Tzourio-Mazoyer, N., Landeau, B., Papathanassiou, D., Crivello, F., Etard, O., Delcroix, N., et al. (2002). Automated anatomical labeling of activations in SPM using a macroscopic anatomical parcellation of the MNI MRI single-subject brain. Neuroimage, $15,273-289$.

van der Meulen, M., Logie, R. H., \& Della Sala, S. (2008). Selective interference with visual working memory: Evidence for the workspace model. Quarterly Journal of Experimental Psychology, 62, 1568-1580.

Warrington, E. K., \& James, M. (1991). The visual object and space perception battery. Bury St Edmunds: Thames Valley Test Company.

Weber, R. J., \& Castleman, J. (1970). The time it takes to imagine. Perception and Psychophysics, 8, 165-168.

Wilson, B. A., Alderman, N., Burgess, P. W., Emslie, H., \& Evans, J. J. (1996). The behavioural assessment of the dysexecutive syndome. Bury St Edmunds: Thames Valley Test Company.

Young, A. W., \& van de Wal, C. (1996). Charcot's case of impaired imagery. In C. Code, C.-W. Wallesch, Y. Joanette, \& A. R. Lecours (Eds.), Classic cases in neuropsychology (pp. 31-44). Hove: Psychology Press.

Zigmond, A. S., \& Snaith, R. P. (1983). The hospital anxiety and depression scale. Acta Psychiatrica Scandinavica, 67, 361-370. 